\title{
Polymyositis presenting as sick sinus syndrome
}

\author{
Peter G. Reid \\ M.B., Ch.B. \\ I. N. F. MCQUEEN* \\ M.B., Ch.B., M.R.C.P. \\ B. E. GRIFFITHS \\ M.B., Ch.B., M.R.C.P. \\ J. J. DALAL \\ M.D.
}

Departments of Cardiology and *Neurology, University Hospital of Wales, Heath Park, Cardiff CF4 4XW

\begin{abstract}
Summary
A 39-year-old woman presented with palpitations, presyncope and muscular weakness. Electrocardiographic monitoring and electrophysiological studies confirmed the tachycardia-bradycardia form of the sick sinus syndrome and subsequent investigations including an endomyocardial biopsy demonstrated polymyositis as the cause.
\end{abstract}

\section{Introduction}

Myocardial involvement in polymyositis has been increasingly recognized since it was first reported by Oppenheim (1899). Cardiac manifestations include congestive cardiac failure (Lynch, 1971; Bohan et al., 1977; Denbow et al., 1979), pericarditis (Lynch, 1971), atrioventricular and bundle branch block (Lynch, 1971, Schaumburg, Nielsen and Yurchak, 1971; Henderson et al., 1980) and atrial and ventricular arrhythmias (Devere and Bradley, 1975; Bohan et al., 1977; Sharratt, Danta and Carson, 1977; Denbow et al., 1979). Polymyositis however is not a well recognized cause of the tachycardiabradycardia form of the sick sinus syndrome.

\section{Case report}

A 39-year-old woman presented with a 9-month history of episodic palpitations shown on the electrocardiogram (ECG) to be due to atrial tachycardia. Five days after starting treatment with nadolol $(40 \mathrm{mg} /$ day) she became very weak and lightheaded and was found to be peripherally vasoconstricted with a heart rate of 35 beats $/ \mathrm{min}$ and systolic blood pressure of $65 \mathrm{mmHg}$. ECG showed a junctional rhythm with no underlying abnormality. The haemodynamic state improved in $24 \mathrm{hr}$ following withdrawal of nadolol, commencement of inotropic support and temporary pacing. Chest X-ray and echocardiogram were normal. Specific enquiry revealed that she had experienced generalized muscle weakness for 6 years and examination showed a symmetrical myopathy. ESR was persistently raised (to $60 \mathrm{~mm} / \mathrm{hr}$ ) as was the serum creatine kinase (1180 i.u./l, 4\% MB isoenzyme). Electromyography demonstrated clear-cut myopathic units with profuse spontaneous fibrillation and positive sharp waves indicating inflammatory change. Skeletal muscle biopsy confirmed the diagnosis of polymyositis. There was no evidence of osteomalacia, Cushing's syndrome, thyroid dysfunction, sarcoidosis, rheumatoid arthritis, or systemic lupus erythematosus. Viral antibody titres were all low. Over subsequent weeks she remained in junctional or slow ectopic atrial rhythm with frequent atrial and ventricular ectopics and self terminating episodes of atrial tachycardia. Cardiac electrophysiology performed two weeks after withdrawal of all therapy demonstrated an ectopic atrial tachycardia (210/ min) with $2: 1$ atrioventricular block, unresponsive to atrial and ventricular premature stimuli, atrial overdrive pacing or verapamil $(10 \mathrm{mg}$ i.v.), but slowing to $185 / \mathrm{min}$, with $1: 1$ conduction and normal HV interval, after disopyramide (100 mg i.v.). Cardioversion resulted in a temporary junctional rhythm, reverting to a slow ectopic atrial rhythm and then atrial tachycardia. At no time was sinus rhythm documented. Cardiac catheterization showed normal haemodynamic measurements and a normal left ventricular angiogram. Left ventricular endocardial biopsy demonstrated a mild lymphocytic infiltration with irregularity of the muscle fibres, consistent with polymyositis.

\section{Discussion}

Myocardial involvement in polymyositis has been increasingly recognized despite infrequent symptomatic presentation. ECG abnormalities are common (Denbow et al., 1979) and autopsy studies have confirmed myocardial involvement with swelling and degeneration of interstitial tissue, focal necrosis, round cell infiltration and replacement fibrosis in 
the atria, ventricles, sino-atrial node and HisPurkinje system (Lynch, 1971; Hill and Barrows, 1968; Schaumburg et al., 1971; Denbow et al., 1979). Our patient presented with the tachycardiabradycardia form of the sick sinus syndrome, an unusual presentation for chronic polymyositis. Endomyocardial biopsy provided ante-mortem confirmation of cardiac involvement. Our case emphasizes the need to exclude an underlying connective tissue disease such as polymyositis in patients presenting with this syndrome.

\section{Acknowledgments}

We are grateful for the help of Dr Gillian Cole and Dr Alan R. Gibbs, Senior Lecturers in the Department of Pathology, Welsh National School of Medicine.

\section{References}

Bohan, A., Peter, J.B., Bowman, R.L. \& Pearson, C.M. (1977) Computer-assisted analysis of 153 patients with polymyositis and dermatomyositis. Medicine (Baltimore), 56, 255.

Denbow, C.E., Lie, J.T., TANCREdi, R.G. \& BunCh, T.W. $\stackrel{\circledR}{\circledR}$ (1979) Cardiac involvement in polymyositis. Arthritis and $C$ Rheumatism, 22, 1088.

DeVere, R. \& BRAdley, W.G. (1975). Polymyositis: Its presentation, morbidity and mortality. Brain, 98, 637.

Henderson, A., Cumming, W.J.K., Williams, D.O., \& Hudgson, P. (1980) Cardiac complications of polymyositis. Journal of the Neurological Sciences, 47, 425.

Hill, D.L. \& BarRows, H.S. (1968). Identical skeletal and $\mathbb{\Phi}$ cardiac muscle involvement in a case of fatal polymyositis. Archives of Neurology, 19, 545.

LYNCH, P.G. (1971) Cardiac involvement in chronic poly- $\overrightarrow{0}$ myositis. British Heart Journal, 33, 416.

OPPENHEIM, H. (1899) Zur dermatomyositis. Berliner Kiinische $\overrightarrow{\vec{\omega}}$ Wochenschrift, 36, 805.

Schaumburg, H., Nielsen, S.L. \& Yurchak, P.M. (1971) Heart block in polymyositis. New England Journal of 3 Medicine, 284, 480.

Sharratt, G.P., Danta, G. \& Carson, P.H.M. (1977) Cardiac abnormality in polymyositis. Annals of Rheumatic Disease, 36, 575. 